\title{
Systematic review and meta-analysis of metacestodes prevalence in small ruminants in Ethiopia
}

\author{
Kassahun Asmare ${ }^{\mathrm{a}, *}$, Berhanu Sibhat ${ }^{\mathrm{b}}$, Mesele Abera ${ }^{\mathrm{a}}$, Aynalem Haile $^{\mathrm{c}}$, Hailu Degefu ${ }^{\mathrm{d}}$, \\ Tsegaw Fentie ${ }^{\mathrm{e}}$, Jemere Bekele ${ }^{\mathrm{a}, \mathrm{h}}$, , Getachew Terefe $^{\mathrm{f}}$, Barbara Szonyi ${ }^{\mathrm{g}}$, Lucy J. Robertson ${ }^{\mathrm{h}}$, \\ Barbara Wieland ${ }^{g}$ \\ a School of Veterinary Medicine, Hawassa University, P.O. Box 005, Hawassa, Ethiopia \\ b College of Veterinary Medicine, Haramaya University, P.O. Box 138, Dire Dawa, Ethiopia \\ ' International Center for Agricultural Research in the Dry Areas (ICARDA), Ethiopia Research Platform, Sub-Saharan Africa Regional Program. P.O. Box. \\ 5689, Addis Ababa, Ethiopia \\ ${ }^{\mathrm{d}}$ College of Agriculture and Veterinary Medicine, Jimma University, P.O. Box 307, Jimma, Ethiopia \\ e Faculty of Veterinary Medicine, University of Gondar, P O. Box 196, Gondar, Ethiopia \\ ${ }^{\mathrm{f}}$ College of Agriculture and Veterinary Medicine, Addis Ababa University, P.O. Box 34, Debre-Zeit, Ethiopia \\ ${ }^{\mathrm{g}}$ International Livestock Research Institute (ILRI), P.O. Box 5689, Addis Ababa, Ethiopia \\ ${ }^{\mathrm{h}}$ Norwegian University of Life Sciences, P.O. Box 8146 dep., N-0033 Oslo, Norway
}

\section{A R T I C L E I N F O}

\section{Article history:}

Received 1 March 2016

Received in revised form 9 May 2016

Accepted 12 May 2016

\section{Keywords:}

Ethiopia

Metacestodes

Meta-analysis

Prevalence

Small ruminants

\section{A B S T R A C T}

Metacestodes, the larval stages of canid cestode parasites, are among the causes of morbidity, mortality and financial losses in small ruminants in Ethiopia as a result of organ and carcass condemnation at slaughter. Several studies have been conducted over the years; however, these studies often had limited scope and coverage. This systematic review and meta-analysis was conducted to collate the information so far available in order to provide a pooled prevalence estimate at national level and identify potential predictors. Published and grey literature written in English and Amharic in the period from, 1st of January 1990 to June 25, 2015 were searched from electronic databases and repositories of academic and research institutions. Relevant animal level data on 67,743 small ruminants was extracted from 23 published articles and one master's thesis resulting altogether in 86 animal level reports that conformed to predefined criteria. The dataset was analyzed using a meta-analytical approach. The pooled prevalence estimate computed for metacestodes infection was $11.8 \%$ with a $95 \%$ confidence interval (CI) of 9.1, 15.4. The highest prevalence estimate 31.2\% (95\% CI: 23.1, 40.9) was found for Cysticercus tenuicollis (Taenia hydatigena) followed by cystic echinococcosis (Echinococcus granulosus) 8.8\% (95\% CI: 5.8, 13.1), Cysticercus ovis (Taenia ovis) 4.9\% (95\% CI: 2.9, 9.4) and Coenurus cerebralis (Taenia multiceps) 4.6\% (95\% CI: 1.6, 12.2). Among the predictors considered for heterogeneity analysis only sample size and metacestode type fitted the final multivariable meta-regression model and explained $26.3 \%$ of the explainable heterogeneity between studies $(\mathrm{p}<0.05)$. The prevalence was noted to decrease with increasing sample size. No significant difference in prevalence was observed between sheep and goats $(p>0.05)$. In conclusion, this review showed a widespread occurrence of metacestodes in small ruminants in Ethiopia. Thus, a holistic approach to break the life cycle of these parasitic stages is suggested, including regulatory interventions that encourage dog owners to keep their dogs confined and prevent backyard slaughter and proper management of abattoir waste disposal.

(c) 2016 Elsevier B.V. All rights reserved.

\footnotetext{
* Corresponding author.

E-mail addresses: Ka7588@yahoo.com, kassahun7588@gmail.com (K. Asmare).
}

\section{Introduction}

Ethiopia has a combined sheep and goat populations exceeding 49 million (CSA, 2013), meaning that it is one of the largest populations of small ruminants in Africa. Sheep and goat are integral to the livestock production systems in crop-livestock mixed agriculture in the highlands and in the pastoral and agro-pastoral livestock 
production in the lowlands. However, the benefits obtained from small ruminants to date do not match their potential. Among the constraints of small ruminant production are diseases, particularly parasitic diseases including cestodes for which ruminants act as definitive hosts and, more importantly, metacestodes (larvae) of canid taeniid parasites for which they act as intermediate hosts (Njau et al., 1988; Biffa et al., 2007).

Several cestode species affect small ruminants in Ethiopia; however they are seldom diagnosed as a cause of clinical diseases although metacestodes of different cestode parasites of carnivores have been recognized as major causes of economic losses from organ condemnation during slaughter (Sissay et al., 2008; Kumsa and Mohammedzein, 2014). Metacestodes (larval stages) of cestode parasites of canids reported in small ruminants in Ethiopia include metacestodes of Echinococcus granulosus (cystic echinococcosis or hydatid cyst), Taenia hydatigena (Cysticercus tenuicollis), Taenia ovis (Cysticercus ovis) and Taenia multiceps (Coenurus cerebralis). Most of these parasitic stages, except Coenurus cerebralis, were reported from apparently healthy animals slaughtered for human consumption. Besides organ condemnation (Jibat et al., 2008; Regassa et al., 2013), Coenurus cerebralis was reported as a primary cause of clinical disease and mortality in highland sheep of central Ethiopia (Njau et al., 1988; Achenef et al., 1999).

Although, a number of reports are available on various metacestodes of small ruminants in Ethiopia, the prevalence data are affected by the type of study population, sample size and other host or environment related study factors. Thus it is important to obtain a larger scale overview and identify potential predictors of infection dynamics in the population of interest, in order to develop an informed intervention plan. This systematic review and metaanalysis aims at estimating the pooled prevalence and identifying the predictors that could contribute to the heterogeneity between the reports. This work was intended to provide a summarized information to livestock health policy makers and fellow researchers by analyzing and interpreting the data available.

\subsection{Material and methods}

\subsubsection{Study protocol}

A protocol addressing the review questions was developed. This included identification of outcomes of interest and defining inclusion and exclusion criteria. Two different kinds of guidelines and a data extraction template were developed. The first was a guideline for preliminary screening focusing on title and abstract content. The second guideline included specific criteria to assist in identifying valid studies that were in line with the objective of the study, had reliable methodology, data analysis, result presentation and conclusion reached. The data extraction template facilitated capturing of outcome of interest from valid studies. The guidelines and the template were reviewed before use. The approach ensured compliance with PRISMA guideline for review processes (Moher et al., 2009).

\subsection{Literature search strategy}

The literature search strategy was both electronic and manual. Electronic searches were done using PubMed, Web of Science, Cab Direct, Google scholar and African journals on line. The key electronic search strings used were "small ruminants", "sheep", "goats", "metacestode", "hydatidosis", "Coenurosis", "Cystic echinococcosis" "Cysticercus tenuicollis", "Cysticercus ovis", Taenia hydatigena", "Echinococcus granulosus", "Taenia ovis", "Taenia multiceps" "Gastrointestinal parasites", "and 'Ethiopia'. The keywords/strings were rearranged to phrases close to metacestodes infection in small ruminants in Ethiopia. The terms 'sheep'; 'goats'; or 'small ruminants' were used together with 'Ethiopia' at all times. To increase the chance of recovering additional articles that might be missed in the electronic search process; the reference lists of published manuscripts with the subject of interest were crosschecked. The searches for unpublished manuscripts were done at Addis Ababa; Haramaya; Jimma; Gondar and Hawassa universities; the ministry of Agriculture; and at the repository of the International Livestock Research Institute (ILRI); Addis Ababa. The last search was conducted on June $25 ; 2015$.

\subsection{Inclusion and exclusion criteria}

Manuscripts written in English or Amharic (official working language of Ethiopia) which were either published or grey literature were retrieved electronically or manually. The preliminary assessments of the reports were done by scanning the title and abstracts. Then manuscripts were further assessed for quality standard in line with predefined criteria. The specific inclusion criteria were as follows: 1) species of concern (sheep and goats);2) clarity of objective; 3 ) appropriateness of methodology including internal validity of the reports; 4 ) result presentation and clarity; 5) studies conducted between January 1990 and June 2015. The quality standard of each manuscript was assessed independently by two authors. When any of the data extractors (co-authors) found a manuscript difficult to judge, the first author was consulted and eventual differences discussed to reach a consensus decision on whether to include or exclude the manuscript. The resulting dataset was double checked against the source before analysis.

\subsection{Data extraction}

The data extracted included year of publication, study area, agro-ecology, production system, species, sex, age, study design, diagnostic method, sample size, number positives, number of negatives, prevalence and respective $95 \%$ confidence interval and parasitic category. In some of the reports, where specific parametric estimates were lacking, i.e. confidence intervals of point estimates or number positives, further analysis of the data was done to capture the missing values.

\subsection{Data analysis}

The statistical software used in the analysis was STATA 12.1 version (stata corp 4905 Lakeway Drive College Station, Texas 77845 USA). The software was first updated for meta-analytical user written packages. Then data extracted was pasted and logit transformed using the formula: $\operatorname{lp}=\ln [\mathrm{p} /(1-\mathrm{p})]$, where $\mathrm{lp}=$ the logit event estimate; $\ln =$ the natural logarithm; $\mathrm{p}=$ study level estimate. The variance of the logit estimate was calculated using the formula $\mathrm{v}(\mathrm{lp})=1 /(\mathrm{np})+1 /[\mathrm{n}(1-\mathrm{p})]$, where $\mathrm{v}=$ variance and $\mathrm{n}=$ sample size. Using transformed values, the pooled prevalence estimate was calculated using the formula, $p=1 /\left(1+e^{-l p}\right)^{*} 100$, where ' $e$ ' is the base of natural logarithm.

\subsection{Heterogeneity analysis}

In order to identify sources of heterogeneity in prevalence estimates among studies, the Cochran's $Q$ statistics indicating differences in true Effect Size (ES) was calculated. The observed heterogeneity was ignored if the ratio of $Q$ and degree of freedom (df) were less than one. Moreover tau statistics $\left(\tau^{2}\right)$ that assesses the true variation between studies was conducted. The inverse variance index $\left(I^{2}\right)$ was also used to assess the percentage of the variation attributable to heterogeneities between studies and when it exceeded $25 \%$, the predictors were fitted in a meta-regression 


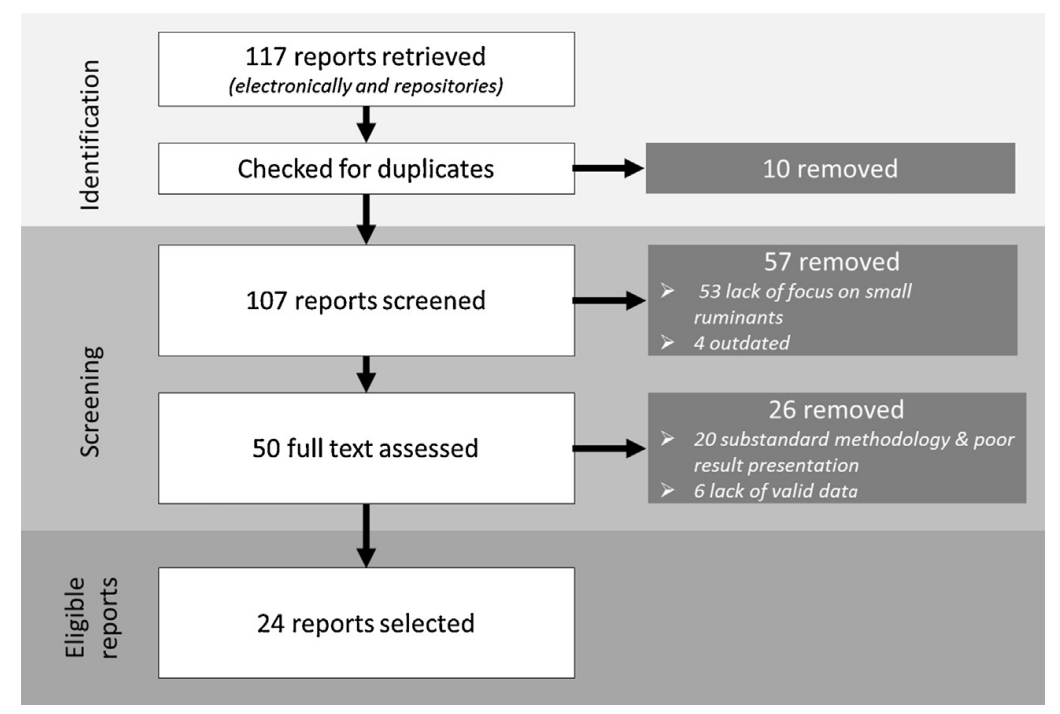

Fig. 1. Schematic flow diagram of literature selection for systematic review on metacestode infection in small ruminants in Ethiopia.

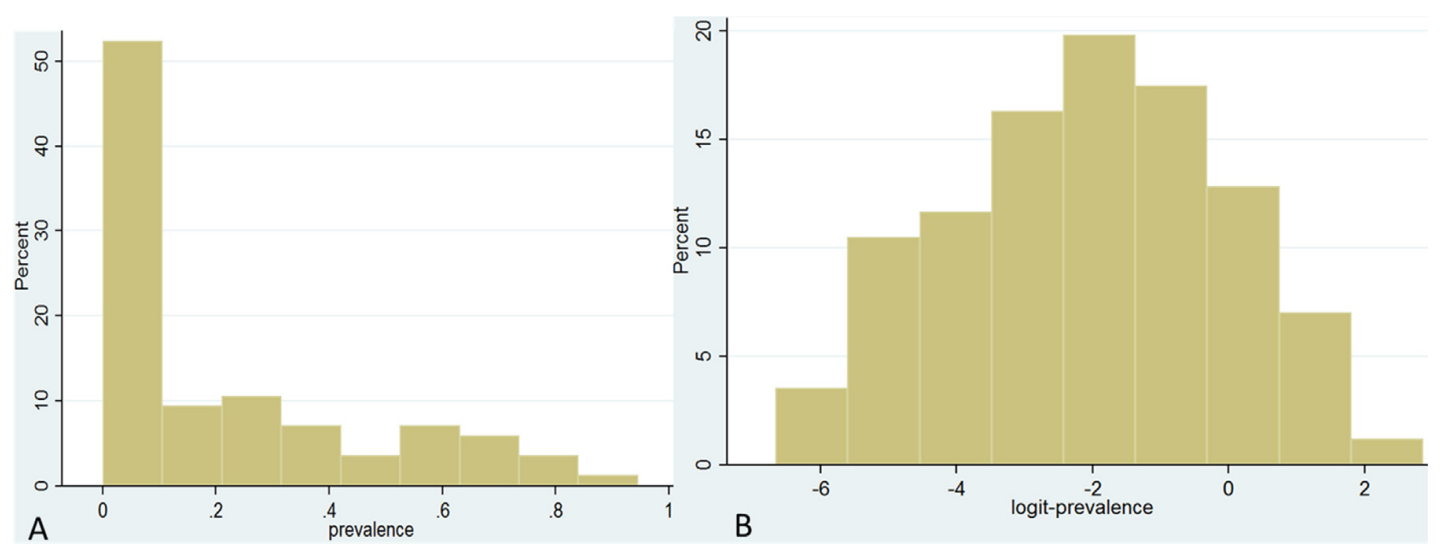

Fig. 2. Apparent (A) and logit-prevalence (B) estimate distributions for the animal-level studies of metacestode infection in small ruminants in Ethiopia.

model to quantify between-groups explainable proportion or subjected to subgroup analysis (Higgins and Thompson, 2002; Hox and de Leeuw, 2003). In this analysis, statistical significance was set at $\mathrm{p}<0.05$.

\subsection{Meta-regression}

The meta-regression model was constructed to estimate the additive (between-study) component of the variance $t a u^{2}$. In the analysis, predictors were first assessed for their independent effect in univariable meta-regression analysis. Those variables with $p$-values $\leq 0.25$ were further subjected to multivariable metaregression analysis. This helped to identify the likely predictors that could be assumed to have significant effect and state the explainable proportion of the variability between groups $\left(R^{2}\right)$. Basically $R^{2}$ value ranges between 0 and 1 , but when the sampling error yielded a value outside the specified range in the univariable metaregression, the calculated values were set to either 0 if negative, or to 1 when it was above 1 (Borenstein et al., 2009).

\subsection{Bias assessment}

The study design and methodology of studies were assessed to observe the within-study bias. Funnel plots were used to obtain visual impressions across-study bias and the Begg's and Egger's tests were used to assess the statistical significance of the bias noted (Sterne et al., 2009; Borenstein et al., 2009).

\section{Results}

\subsection{Literature search results}

The electronic and manual search resulted in 117 publications and graduate and undergraduate thesis. Fifty seven of them were automatically rejected following assessment of title and abstracts. At closer inspection of the individual manuscripts, 26 of them had lack of usable data or methodology below the pre-defined standard, mainly due to sampling procedure and study design that forced us to question the internal validity of the estimates for the study population. Ten of them were redundant both in thesis and articles. Finally 23 published articles and one master's thesis met the minimum acceptable standard to be included in this review (Fig. 1). Eighteen of these articles had data on cystic echinococcosis (hydatid cyst), 11 on Cysticercus tenuicollis, five on Cysticercus ovis and data on Coenurus cerebralis was acquired from four articles. Altogether 86 animal level data were retrieved on regions and species level for all four metacestodes (Table 1). However, as much of the small ruminant data were obtained from abattoirs, information on the 
Table 1

Metacestode studies reports included in a meta-analysis of small ruminant's pooled prevalence estimate $(\mathrm{n}=86)$.

\begin{tabular}{|c|c|c|c|c|c|c|}
\hline Author & Agent & Spp & Region & Agroecology & Sample size & $\operatorname{APP}(\%)$ \\
\hline Sissay et al. (2008) & C. ovis & Ovi & Oromia & $\mathrm{HL}$ & 308 & 27.3 \\
\hline Sissay et al. (2008) & C. tenuicollis & Ovi & Oromia & $\mathrm{HL}$ & 308 & 77.3 \\
\hline Sissay et al. (2008) & C. ovis & Ovi & D. Dawa & LL & 166 & 13.3 \\
\hline Sissay et al. (2008) & C. tenuicollis & Ovi & D. Dawa & LL & 166 & 81.9 \\
\hline Sissay et al. (2008) & C. ovis & Ovi & Somali & LL & 181 & 34.3 \\
\hline Sissay et al. (2008) & C. tenuicollis & Ovi & Somali & LL & 181 & 79.6 \\
\hline Sissay et al. (2008) & C. ovis & Cap & Oromia & $\mathrm{HL}$ & 302 & 19.5 \\
\hline Sissay et al. (2008) & C. tenuicollis & Cap & Oromia & $\mathrm{HL}$ & 302 & 48.3 \\
\hline Sissay et al. (2008) & C. ovis & Cap & D. Dawa & LL & 159 & 23.3 \\
\hline Sissay et al. (2008) & C. tenuicollis & Cap & D. Dawa & LL & 159 & 57.9 \\
\hline Sissay et al. (2008) & C. ovis & Cap & Somali & LL & 171 & 26.3 \\
\hline Sissay et al. (2008) & C. tenuicollis & Cap & Somali & LL & 171 & 57.3 \\
\hline Samuel and Zewde (2010) & C. tenuicollis & Ovi & US & US & 630 & 40.0 \\
\hline Samuel and Zewde (2010) & C. tenuicollis & Cap & US & US & 768 & 46.6 \\
\hline Bayu et al. (2013) & C. tenuicollis & Ovi & US & US & 576 & 7.8 \\
\hline Bayu et al. (2013) & C. tenuicollis & Cap & US & US & 575 & 15.8 \\
\hline Achenef et al. (1999) & C. cerebralis & Ovi & Amhara & $\mathrm{HL}$ & 187 & 2.7 \\
\hline Jibat et al. (2008) & C. tenuicollis & Cap & US & US & 1536 & 8.3 \\
\hline Jibat et al. (2008) & C. tenuicollis & Ovi & US & US & 1152 & 5.3 \\
\hline Jibat et al. (2008) & C. ovis & Cap & US & US & 1536 & 0.5 \\
\hline Jibat et al. (2008) & C. ovis & Ovi & US & US & 1152 & 0.4 \\
\hline Gessese et al. (2014) & C. tenuicollis & Ovi & Amhara & $\mathrm{HL}$ & 328 & 43.6 \\
\hline Gessese et al. (2014) & C. tenuicollis & Cap & Amhara & LL & 276 & 52.9 \\
\hline Gessese et al. (2014) & C. ovis & Ovi & Amhara & $\mathrm{HL}$ & 328 & 8.2 \\
\hline Gessese et al. (2014) & C. ovis & Cap & Amhara & LL & 182 & 8.8 \\
\hline Deressa et al. (2012) & C. cerebralis & Ovi & US & $\mathrm{HL}$ & 445 & 4.7 \\
\hline Sissay et al. (2008) & $\mathrm{CE}$ & Ovi & Oromia & $\mathrm{HL}$ & 308 & 72.4 \\
\hline Sissay et al. (2008) & $\mathrm{CE}$ & Cap & Oromia & $\mathrm{HL}$ & 302 & 61.9 \\
\hline Sissay et al. (2008) & $\mathrm{CE}$ & Ovi & D. Dawa & LL & 166 & 57.8 \\
\hline Sissay et al. (2008) & $\mathrm{CE}$ & Cap & D. Dawa & LL & 159 & 67.3 \\
\hline Sissay et al. (2008) & $\mathrm{CE}$ & Ovi & Somali & LL & 181 & 69.1 \\
\hline Sissay et al. (2008) & $\mathrm{CE}$ & Cap & Somali & LL & 171 & 69.0 \\
\hline Bayu et al. (2013) & CE & Ovi & US & US & 576 & 4.0 \\
\hline Bayu et al. (2013) & $\mathrm{CE}$ & Cap & US & US & 576 & 1.2 \\
\hline Desta et al. (2012) & $\mathrm{CE}$ & Ovi & Tigray & $\mathrm{HL}$ & 1152 & 11.6 \\
\hline Erbeto et al. (2010) & $\mathrm{CE}$ & Ovi & US & US & 1554 & 13.3 \\
\hline Erbeto et al. (2010) & $\mathrm{CE}$ & Cap & US & US & 639 & 16.0 \\
\hline Giro et al. (2014) & $\mathrm{CE}$ & Ovi & US & US & 6680 & 9.15 \\
\hline Giro et al. (2014) & $\mathrm{CE}$ & Cap & US & US & 20059 & 0.13 \\
\hline Marshet et al. (2011) & $\mathrm{CE}$ & Ovi & US & US & 611 & 13.9 \\
\hline Marshet et al. (2011) & $\mathrm{CE}$ & Cap & US & US & 389 & 3.1 \\
\hline Getachew et al. (2012) & $\mathrm{CE}$ & Ovi & US & US & 325 & 7.7 \\
\hline Getachew et al. (2012) & CE & Cap & US & US & 440 & 6.1 \\
\hline Kebede et al. (2009) & CE & Ovi & Amhara & ML & 340 & 10.6 \\
\hline Degefu and Damet (2013) & $\mathrm{CE}$ & Ovi & Amhara & $\mathrm{HL}$ & 197 & 7.6 \\
\hline Jibat et al. (2008) & $\mathrm{CE}$ & Cap & US & US & 1536 & 1.8 \\
\hline Jibat et al. (2008) & $\mathrm{CE}$ & Ovi & US & US & 1152 & 0.9 \\
\hline Gessese et al. (2014) & $\mathrm{CE}$ & Ovi & Amhara & ML & 510 & 9.0 \\
\hline Gessese et al. (2014) & $\mathrm{CE}$ & Cap & Amhara & ML & 420 & 1.9 \\
\hline Kumsa and Mohamedzein (2014) & $\mathrm{CE}$ & Ovi & Oromia & ML & 502 & 29.7 \\
\hline Kumsa and Mohamedzein (2014) & $\mathrm{CE}$ & Cap & Oromia & ML & 302 & 24.8 \\
\hline Gessese et al. (2014) & $\mathrm{CE}$ & Ovi & Amhara & $\mathrm{HL}$ & 288 & 8.3 \\
\hline Gessese et al. (2014) & CE & Cap & Amhara & LL & 132 & 9.1 \\
\hline Ragassa et al. (2013) & C. tenuicollis & Cap & US & US & 451 & 2.7 \\
\hline Ragassa et al. (2013) & C. tenuicollis & Ovi & US & US & 674 & 6.8 \\
\hline Ragassa et al. (2013) & C. cerebralis & Ovi & US & US & 451 & 6.4 \\
\hline Ragassa et al. (2013) & C. cerebralis & Cap & US & US & 674 & 2.1 \\
\hline Ragassa et al. (2013) & C. ovis & Ovi & US & US & 451 & 0.4 \\
\hline Ragassa et al. (2013) & C. ovis & Cap & US & US & 674 & 0.6 \\
\hline Ragassa et al. (2013) & $\mathrm{CE}$ & Ovi & US & US & 451 & 0.2 \\
\hline Ragassa et al. (2013) & $\mathrm{CE}$ & Cap & US & US & 674 & 0.6 \\
\hline Abdella (2006) & C. tenuicollis & Ovi & US & US & 738 & 32.7 \\
\hline Abdella (2006) & $\mathrm{CE}$ & Ovi & US & US & 738 & 2.4 \\
\hline Abdella (2006) & C. ovis & Ovi & US & US & 738 & 1.4 \\
\hline Abdella (2006) & C. cerebralis & Ovi & US & US & 738 & 0.7 \\
\hline Abdella (2006) & C. tenuicollis & Cap & US & US & 738 & 34.7 \\
\hline Abdella (2006) & $\mathrm{CE}$ & Cap & US & US & 738 & 2.6 \\
\hline Abdella (2006) & C. ovis & Cap & US & US & 738 & 0.3 \\
\hline Abdella (2006) & C. cerebralis & Cap & US & US & 738 & 3.8 \\
\hline Getaw et al. (2010) & $\mathrm{CE}$ & Ovi & US & US & 92 & 29.3 \\
\hline Getaw et al. (2010) & $\mathrm{CE}$ & Cap & US & US & 208 & 6.7 \\
\hline Mandefero et al. (2015) & CE & Cap & US & US & 384 & 1.3 \\
\hline Mandefero et al. (2015) & $\mathrm{CE}$ & Ovi & US & US & 384 & 1.0 \\
\hline Mandefero et al. (2015) & C. tenuicollis & Cap & US & US & 384 & 5.7 \\
\hline Mandefero et al. (2015) & C. tenuicollis & Ovi & US & US & 384 & 8.1 \\
\hline
\end{tabular}


Table 1 (Continued)

\begin{tabular}{|c|c|c|c|c|c|c|}
\hline Author & Agent & Spp & Region & Agroecology & Sample size & $\mathrm{APP}(\%)$ \\
\hline Belina et al. (2012) & CE & Cap & Amhara & ML & 400 & 15.0 \\
\hline Mekuria et al. (2013) & C. tenuicollis & Ovi & D. Dawa & LL & 420 & 22.9 \\
\hline Mekuria et al. (2013) & C. tenuicollis & Ovi & D. Dawa & LL & 425 & 26.4 \\
\hline Birhanu (2014) & $\mathrm{CE}$ & Cap & Oromia & US & 109 & 9.2 \\
\hline Birhanu (2014) & CE & Ovi & Oromia & US & 275 & 22.5 \\
\hline Guadu et al. (2012) & C. tenuicollis & Ovi & US & US & 395 & 36.2 \\
\hline Guadu et al. (2012) & C. tenuicollis & Cap & US & US & 415 & 39.5 \\
\hline Wondimu et al. (2011) & C. tenuicollis & Cap & US & US & 576 & 56.8 \\
\hline Wondimu et al. (2011) & C. tenuicollis & Ovi & US & US & 576 & 63.9 \\
\hline
\end{tabular}

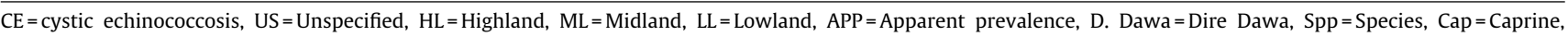
Ovi = Ovine.

origin of the animals, agro-ecology, sex and age related analysis were intentionally avoided, either due to lack of clarity or high possibility of bias in the related findings.

\subsection{Quality of the reports and characteristics of the study}

As per to the predefined inclusion and exclusion criteria, study reports were assessed in two major steps. First preliminary screening for compliance with review question and topicality was done, this was followed by closer assessment of selected reports as per the indexes of the guideline. Finally the extracted data were checked against the source before the analysis. In the selected articles the researchers collected samples from 67,743 small ruminants at least for one species of metacestodes (cystic echinococcosis, C. tenuicollis, C. ovis and C. cerebralis). Among the small ruminants involved in the studies, 28,580 were sheep while the remaining 39,163 were goats. In nineteen of the studies, the designs were cross-sectional but retrospective approaches were also there in five of abattoir reports.

\subsection{Meta-analysis}

The pooled prevalence estimate of metacestode infection in small ruminants was $11.8 \%$ (95\% CI: 9.1, 15.4). In a random effect model, the calculated Cochran value $(Q)$ was $7997.51(\mathrm{df}=85$ and $\mathrm{p}=0.000$ ). The raw and logit-transformed effect size distribution is shown on Fig. 2. The effect size and respective weight of each eligible study report in the review is also presented on the forest plot (Fig. 3). The estimate of $\tau^{2}$ was 1.8534 with inverse variance $\left(I^{2}=98.9 \%\right)$ after notifying significant effect size variation attributable to heterogeneity between studies. The highest pooled prevalence estimates was calculated for $C$. tenuicollis with $31.2 \%$, while lowest was $4.6 \%$ for $C$. cerebralis. The prevalence estimate for cystic echinococcosis was $8.8 \%$ and that of $C$. ovis was $4.9 \%$. The $95 \% \mathrm{CI}$ of the prevalence estimates along with measure of heterogeneities between study reports for each metacestodes are given in Table 2.

\subsection{Subgroup analysis}

In this review the group level estimate was made for sheep and goats. The analysis went further for each type of metacestode except $C$. cerebralis due to lack of sufficient observations per group. The analysis was preceded by collinearity assessment and all of the covariates (host species, year and sample size) were found to have a gamma value between -0.6 and +0.6 . For sheep, the group level metacestode pooled estimate prevalence (excluding $C$. cerebralis) was $14.7 \%$. The corresponding figure for goat was $10.8 \%$ and no statistical significant difference was noted between the groups (Table 3).

\subsection{Meta-regression}

\subsubsection{Effect of sample size}

The effect of sample size was assessed in meta-regression. As presented in Table 4, there was a negative association of sample size with metacestode prevalence estimate.

\subsection{Univariable meta-regression}

In this part of the heterogeneity analysis, the predictors considered were host species, parasite species, sample size, and year of report. The regression was conducted with and without controlling sample size as depicted in Table 5. In the course of the analysis adjustment of proportions of estimates was made for species due to negative values (Borenstein et al., 2009). The proportion of explainable variation attributed to the aforesaid predictors range from $5.2 \%$ for sample size to $13.5 \%$ for etiologic agent category. Excluding the species other predictors were subjected to multivariable meta-regression based on the $p$-value $(\mathrm{p}<0.25)$.

\subsection{Multivariable meta-regression}

The three qualifying predictors, namely sample size, year and etiologic agent were fitted into the multivariable meta-regression model. However, in the final model etiologic agent and sample size accounted for $26.3 \%$ of the explainable heterogeneity between the study reports $\left(\tau^{2}\right.$ unexplained $=2.776, \tau^{2}$ total $=4.035$ ). Accordingly, the effect size of $C$. tenuicollis has been observed to increase by $80.2 \%$ from the reference (cystic echinococcosis), while $C$. cerebralis was less abundant and noted to have a prevalence reduced by $14.2 \%$ from cystic echinococcosis. On the other hand, the difference observed between $C$. ovis and cystic echinococcosis was not statistically significant (Table 6). The other factor observed to account for heterogeneity was sample size which ranged from 92 to 20,059. Larger sample size had significant negative association with metacestode prevalence. i.e., the prevalence was observed to decrease with increasing sample size.

\subsection{Publication bias assessment}

In the publication bias analysis the Begg's and Egger's statistics were seen to have p-value $=0.001$ and 0.004 , respectively. The parameters were consistent with what is observed on the funnel plot (Fig. 4) and suggests the presence of bias to the left side that could be linked to more study reports with lower prevalence estimates.

\section{Discussion}

The overall prevalence of metacestodes of canid cestode parasites in small ruminants in Ethiopia was $11.8 \%$. Cysticercus tenuicollis was the most common metacestode reported (31.2\%) 


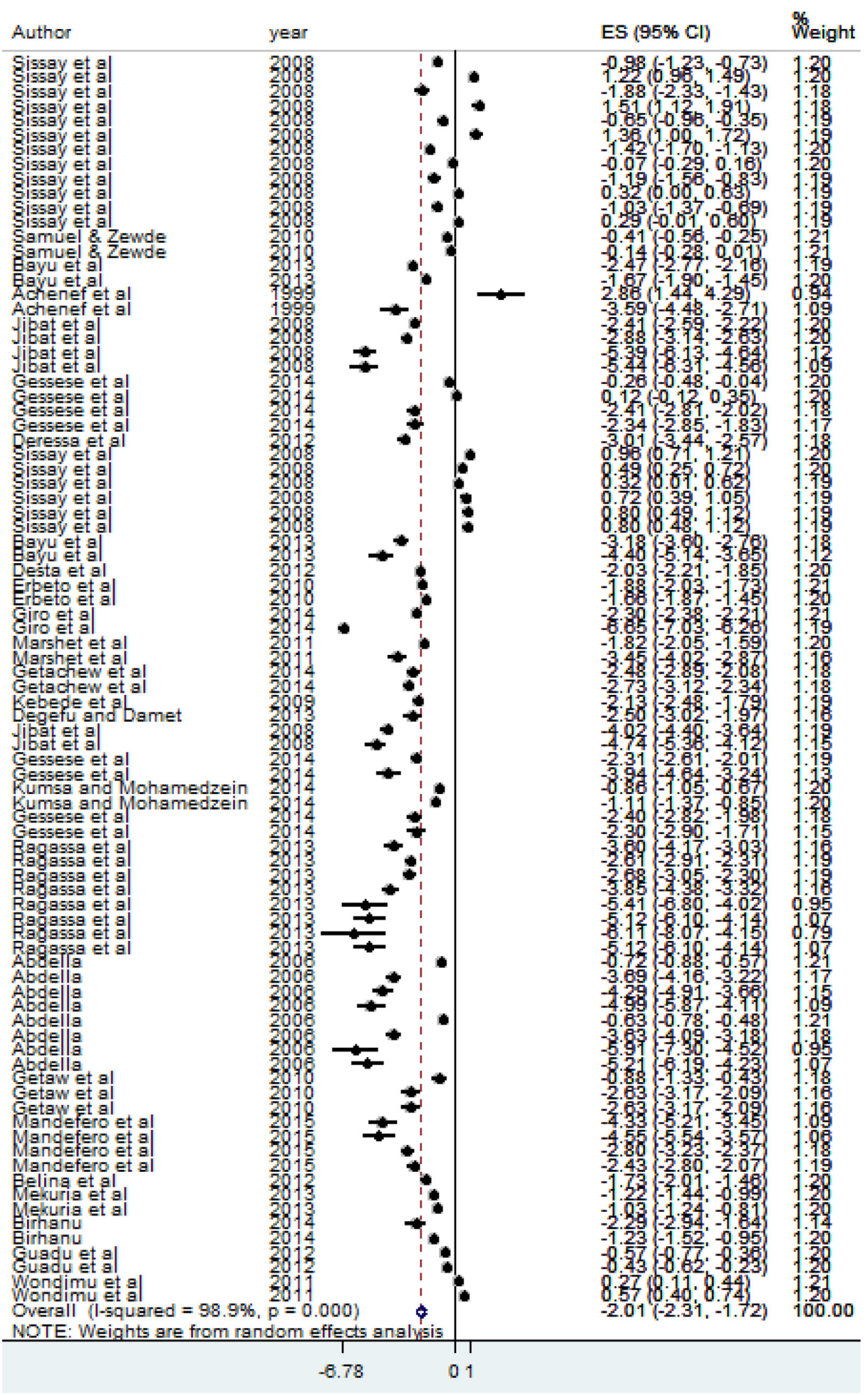

Fig. 3. Forest plot on metacestode infection logit-prevalence estimate in small ruminants in Ethiopia.

whereas the other metacestodes were less prevalent. Similarly, a study conducted in Fars province of Iran found that the prevalence of metacestodes in sheep ranges from less than $1 \%$ to over $28 \%$
(Oryan et al., 1994). Similar to the finding of this systematic review, the same study indicated that $C$. tenuicollis and cystic echinococcosis are more common followed by $C$. cerebralis. Another study 
Table 2

Estimate of pooled prevalence along with their respective meta-cestode and the between study report variance.

\begin{tabular}{|c|c|c|c|c|c|c|}
\hline Metacestodes & Prevalence $(95 \% \mathrm{CI})$ & $\mathrm{Q} / \mathrm{df}$ & df & $\mathrm{p}$ value & $\tau^{2}$ & $\mathrm{I}^{2}$ \\
\hline Overall & $11.8(9.1,15.4)$ & 94.1 & 83 & 0.000 & 1.8534 & 98.9 \\
\hline C. tenuicollis & $31.2(23.1,40.9)$ & 103.9 & 25 & 0.000 & 1.1474 & 98.9 \\
\hline C. ovis & $4.9(2.5,9.4)$ & 35.5 & 13 & 0.000 & 1.7060 & 97.2 \\
\hline C. cerebralis & $4.6(1.6,12.2)$ & 19.4 & 5 & 0.000 & 1.8886 & 94.8 \\
\hline $\mathrm{CE}$ & $8.8(5.8,13.1)$ & 102.4 & 37 & 0.000 & 1.9263 & 98.9 \\
\hline
\end{tabular}

$\mathrm{Q}=$ Heterogeneity chi-square, $\mathrm{df}={ }^{\circ}$ of freedom, $\tau^{2}=$ estimate of between study variance. $\mathrm{I}^{2}=$ Variance in effect size attributable to heterogeneity.

Table 3

Estimate of subgroup pooled metacestodes prevalence in relation to host species.

\begin{tabular}{|c|c|c|c|c|c|c|c|}
\hline Metacestodes & Host spp. & \# report & Prevalence $(95 \% \mathrm{CI})$ & $\mathrm{Q} / \mathrm{df}$ & Q-P & $\mathrm{I}^{2}$ & $\mathrm{p}$ value \\
\hline \multirow[t]{2}{*}{ C. tenuicollis } & Sheep & 13 & $32.3(19.8,48.3)$ & 106.3 & 0.000 & 99.1 & \\
\hline & Goat & 13 & $30.2(19.9,42.8)$ & 86.1 & 0.000 & 98.8 & 0.847 \\
\hline \multirow[t]{2}{*}{$\mathrm{CE}$} & Sheep & 22 & $11.7(7.7,17.5)$ & 69.7 & 0.000 & $98.6 \%$ & \\
\hline & Goat & 17 & $6.1(2.3,15.4)$ & 118.7 & 0.000 & $99.2 \%$ & 0.282 \\
\hline \multirow[t]{2}{*}{ C. ovis } & Sheep & 7 & $5.2(1.8,13.6)$ & 41.9 & 0.000 & $97.6 \%$ & \\
\hline & Goat & 7 & $4.4(1.6,11.8)$ & 34.7 & 0.000 & 97.1 & 0.874 \\
\hline \multirow[t]{2}{*}{ Overall } & Sheep & 47 & $14.7(10.5,20.3)$ & 93.3 & 0.000 & $98.9 \%$ & \\
\hline & Goat & 39 & $10.8(6.9,16.4)$ & 100.5 & 0.000 & $99.0 \%$ & 0.350 \\
\hline
\end{tabular}

$\mathrm{Q}=$ Heterogeneity chi-square, $\mathrm{df}={ }^{\circ}$ of freedom, $\tau^{2}=$ estimate of between study variance. $\mathrm{I}^{2}=$ Variance in effect size attributable to heterogeneity.

Table 4

Coefficients, prevalence and $p$-values from the meta-regression analyses of the associations of sample sizes on metacestode prevalence estimate on small ruminants.

\begin{tabular}{llll}
\hline Unit & Coeff. (logit) & prevalence & p-value \\
\hline Base line(92 animals) & -0.89 & 29.3 & $<0.001$ \\
Sample size & -0.0002 & & \\
\hline
\end{tabular}

Prevalence $=1 /(1+\exp -$ (coefficient).

Table 5

The individual predictor effects proportion and associated statistical significance for heterogeneity observed among the metacestode prevalence studies in a univariable meta-regression model.

\begin{tabular}{|c|c|c|c|c|}
\hline Model & Without sample size & $\mathrm{p}$ value & With sample size & p-value \\
\hline Year & 0.81 & 0.439 & 9.7 & 0.213 \\
\hline Sample size & - & - & 5.2 & 0.006 \\
\hline Species & 0.0 & 0.531 & 9.0 & 0.685 \\
\hline Etiologic agent & 5.5 & 0.133 & 13.5 & 0.069 \\
\hline
\end{tabular}

Table 6

Coefficients and $p$-values of the association on metacestode prevalence in small ruminants meta-regression model $\left(R^{2}=26.29 \%, \mathrm{n}=86 \mathrm{reports}\right)$.

\begin{tabular}{|c|c|c|c|c|c|}
\hline Variables & Predictors category/range & $\mathrm{n}$ & Coeff. & p-value & Over all $p$-value \\
\hline Sample size & $92-20059$ & & -0.0002 & 0.006 & 0.002 \\
\hline \multirow{4}{*}{ Metacestodes } & $\mathrm{CE}$ & 39 & & Reference & \\
\hline & C. ovis & 14 & -0.9 & 0.235 & 0.098 \\
\hline & C. tenuicollis & 26 & 1.4 & 0.004 & 0.009 \\
\hline & C. cerebralis & 7 & -1.8 & 0.064 & 0.025 \\
\hline
\end{tabular}

Coeff. = Coefficient, $\mathrm{n}=$ number of study reports, $\mathrm{P}$ values are all from meta-regression.

in Bangladesh also revealed the presence of three major metacestodes, namely $C$. tenuicollis, cystic echinococcosis and $C$. cerebralis with decreasing order of prevalence (Islam et al., 1995). In Ethiopia, the epidemiology of the adult parasites in the definitive hosts (including dogs and wild canids) is neither well established nor is the demography of canid populations. Hence the real causes of these differences in the prevalence of the metacestodes in small ruminants are not clear for all the metacestodes other than $C$. cerebralis. However, a large proportion of the sample size in the current review is obtained from commercial export abattoirs which slaughter relatively young animals, as compared to local municipal abattoirs. With regard to effect of age on prevalence of cystic echinococcosis and C. tenuicollis in sheep and goats, a study conducted by Torgerson et al. (1998) in northern Jordan, demonstrated an increase in metacestodes prevalence with an increasing age in both species. Nevertheless, our findings do not show a single study made in municipal abattoir or otherwise influencing the prevalence.

Indeed, various studies confirmed that prevalence of ruminants increases with age (Umur, 2003; Azlaf and Dakkak, 2006; Kahnjari et al., 2014; Craig et al., 2015), except for C. cerebralis for which there is an inverse age-prevalence relationship. Thus Coenurus cerebralis is considered as a disease of young animals, more commonly observed in small ruminants between the ages of 3-24 months (Achenef et al., 1999; Scala et al., 2007; Uslu and Guclu 2007; Tavassoli et al., 2011). In countries like Ethiopia, where adult parasites are endemic in dogs and where dogs have free access to pasture, the probability of pasture contamination by cestode ova is high. Animals exposed to infection at an early age are highly susceptible to the acute form of the disease and suffer most (Scott, 2007). Death occurs within an average of 35 days post infection (Achenef et al., 1999). Therefore, the majority of infected animals 


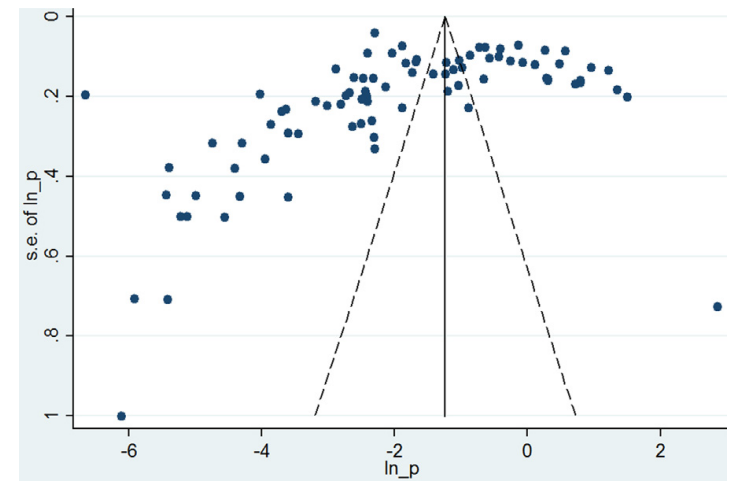

Fig. 4. Funnel plot for logit-prevalence estimate of metacestode infection studies in small ruminants in Ethiopia.

die early as a result of starvation induced by nervous system dysfunction (Njau et al., 1988; Scala and Varcasia, 2006). Alternatively, it could be due to the fact that infection results in an obvious clinical disease, such that the affected animals may not be marketable and are slaughtered at home (Scala et al., 2007; Desouky et al., 2011). Therefore, the lower prevalence of $C$. cerebralis in adult "apparently healthy" small ruminants at abattoir in Ethiopia may partly be due to the preceding facts.

Metacestodes result lead to condemnation of edible visceral organs. Direct financial losses associated with organ condemnation reported for some of the parasites were substantial. In one study conducted in Jimma town by Kumsa and Mohammedzein (2014), the annual loss from liver and lung condemnation from cystic echinococcosis alone was estimated to be 2,493,524 ETB (USD 149,312.8). A similar study conducted in Desie municipal abattoir in north eastern Ethiopia, demonstrated annual financial losses of 3,284,378.29 ETB (USD 178,693.04) from liver and lung condemned due to cystic echinococcosis and C. tenuicollis (Gessese et al., 2014). Other studies from export abattoirs located in central Ethiopia also reported financial losses from organ condemnation associated with metacestodes (Jibat et al., 2008; Regassa et al., 2013). In the light of the preceding facts, the existence of these metacestodes at estimated prevalence in small ruminant stock of consisting 25.5 million sheep and 24.05 million goats (CSA, 2013) is suggestive evidence of the huge economic loss the country suffers due to direct and indirect losses.

Moreover, cystic echinococcosis and $C$. cerebralis are known zoonotic diseases (Oryan and Alidadi, 2015). The presence of these parasites in herbivores in stated proportion is also an indication of the potential environmental contamination with taeniid eggs that could result in human infection. The risk is particularly high in areas where the infrastructure for clean water supply is lacking. Human infections with metacestodes in Ethiopia have been reported only for hydatidosis. Klungsøyr et al. (1993) reported prevalence of $0.7 \%$ $(\mathrm{n}=7 / 990)$ among Hamer people in southern Ethiopia by ultrasonographic examination. Other investigators reported surgical management of 443 patients over a period of 12 years from visceral organs (Ali et al., 2005; Biluts et al., 2006; Minas et al., 2007) and four cases of cerebral hydatidosis in Ethiopia (Assefa et al., 2011). The investigators' report showed that the majority of the patients with the disease were from rural areas of the country and had close contact with dogs. However, reports were based on case records of surgical patients in a major referral hospital, and therefore do not indicate the size of the population at risk in the country, nor reflect the actual prevalence of the disease in the general population.

The observed negative association of prevalence with increasing sample size maybe related to large sample size reports acquired from export abattoirs which slaughter relatively younger animals as already discussed in the previous paragraphs. Besides, much of the small ruminants in the export abattoir were sourced from lowlands where the dog population is relatively low compared with highlands. No significant difference in the prevalence of metacestodes of concern was observed between sheep and goats in this meta-analysis. The reasons could be equal exposure of both sheep and goats to the ova of taeniid parasites in the environment as goats have increasingly been forced to graze rather than browse, due to ever-decreasing resource base of forests and bush lands in Ethiopia (Tschopp et al., 2010).

Information in a review can only be as good as the data used in its generation. There are limitations in our review that need to be considered when interpreting the results of the analysis. Some of the studies used in this meta-analysis had different objectives. Those with the objective of identifying causes of organ condemnation might have given more emphasis to the metacestode(s) in the organs of their interest and might have overlooked the actual prevalence of the metacestode(s) present in other organs or organs with minimal economic importance such as the omentum in the case of $C$. tenuicollis. Despite these limitation, this quantitative review provided a pooled prevalence estimate and gave a wider overview of metacestode occurrence in small ruminants in Ethiopia. Thus these parasitic stages as a cause of mortality, morbidity, and economic losses associated with organ condemnation in small ruminant industry cannot be ignored. Furthermore, the review showed how widespread the infection is. This may indicate potential environmental contamination with taeniid eggs that could also affect human health. The lack of difference in prevalence between sheep and goats could be supportive evidence to the suggested high degree of environmental contamination. Therefore, there is a need for a holistic approach to control metacestode infection; including cultural transformation in waste offal management, regulatory imposition on stray dogs, pet animal management and control of backyard slaughter practice.

\section{Conflict of interest}

None

\section{Author's contribution}

KA \& BS designed, participated in literature search, data extraction, analysis and initial write-up. MA, HD, TF took part in literature search and data extraction. GT, AH, \& JB improved the write- up. LR, BS and BW have critically revisited the manuscript and enriched the discussion. All authors have read and approved the manuscript.

\section{Acknowledgements}

This review was funded through the CGIAR research program on Livestock and Fish. Authors would like to acknowledge the International Center for the Agricultural Research in Dry Areas (ICARDA) and International Livestock Research Institute (ILRI) for facilitating this review. Researchers who devoted their time and resource on this important topic is also very much appreciated. Drs Barbara Rischkowsky, Henry Kiara, Takele Abayneh and Berhanu Admassu are greatly acknowledged for all sorts of technical and logistical support they provided.

\section{References}

Abdella, A., 2006. Metacestodes of Small Ruminants: Prevalence at Three Export Abattoirs (Elfora, Hashim and Luna) MSc Thesis. Faculty of Veterinary Medicine, Addis Ababa University, Debre Zeit, Ethiopia.

Achenef, M., Markos, T., Feseha, G., Hibret, A., Tembely, S., 1999. Coenurus cerebralis infection in ethiopian Highland sheep: incidence and observations on pathogenesis and clinical signs. Trop. Anim. Health Prod. 31, 15-24. 